\title{
High growth rate deposition of oriented hexagonal InN films
}

\author{
Fuh-Hsiang Yang ${ }^{\mathrm{a}}$, Jih-Shang, Hwang ${ }^{\mathrm{b}}$, Kuei-Hsien Chen ${ }^{\mathrm{b}, *}$, Ying-Jay Yang ${ }^{\mathrm{a}}$, Tzung-Han Lee ${ }^{\mathrm{c}}$, Luu- \\ Gen Hwa ${ }^{\mathrm{c}}$, Li-Chyong Chen ${ }^{\mathrm{d}}$ \\ anstitute of Electrical Engineering, National Taiwan University, Taipei, Taiwan \\ ${ }^{\mathrm{b}}$ Institute of Atomic and Molecular Sciences, Academia Sinica, Taipei, Taiwan \\ ${ }^{\mathrm{c}}$ Department of Physics, Fu-Jen University, Taipei County, Taiwan \\ ${ }^{\mathrm{d}}$ Center for Condensed Matter Sciences, National Taiwan University, Taipei, Taiwan
}

Received 26 October 2000; received in revised form 19 October 2001; accepted 28 November 2001

\begin{abstract}
Highly oriented nanocrystalline indium nitride $(\mathrm{InN})$ films were successfully grown on $\mathrm{Si}(111)$ substrate. The growth rate of InN film can be enhanced fourfold by a double-zone metal organic chemical vapor deposition system consisting of a high temperature $\mathrm{NH}_{3}$ pre-cracking zone and a low temperature deposition zone. A maximum growth rate of $6 \mu \mathrm{m} / \mathrm{h}$ was achieved due to the high cracking efficiency of $\mathrm{NH}_{3}$. Meanwhile, the growth temperature of the substrate can be varied from 350 to 600 ${ }^{\circ} \mathrm{C}$, which provides more flexibility for the film structure. While X-ray diffraction revealed the (0001) texture of the film, the high-resolution transmission electron microscopy study concluded the growth of highly oriented nanocrystalline hexagonal InN, which may lead to potential solar cell and optoelectronic applications. (C) 2002 Elsevier Science B.V. All rights reserved.
\end{abstract}

Keywords: Indium nitride; Nanostructures; MOCVD; Raman; TEM

\section{Introduction}

Indium nitride ( $\mathrm{InN}$ ), a III- $\mathrm{V}$ compound semiconductor with a stable wurtzite crystal structure and a direct band gap of $1.9 \mathrm{eV}$ [1], is promising for visible optoelectronics and high efficiency solar cells. It is predicted that a tandem solar cell with a $\mathrm{Si}$ cell at the bottom and a higher bandgap cell of $1.85 \mathrm{eV}$ on the top can achieve a maximum efficiency of $32.1 \%$ (AM1.5 global) [2], which is highly desirable for energy applications. Therefore, the $1.9 \mathrm{eV}$ bandgap $\mathrm{InN}$ has the potential to be used for non-toxic, high efficiency solar cells when integrated with $\mathrm{Si}$. So far, most of the $\mathrm{InN}$ growth studies have been done on sapphire, GaN and GaAs [3-8], except for a few works done on the $\mathrm{Si}$ substrate $[9,10]$. Various methods have been used including metal organic chemical vapor deposition (MOCVD) [3-8], magnetron sputtering [11], molecular beam epitaxy (MBE) [12], halogen-transport vapor phase epitaxy (VPE) [13], and laser-assisted CVD using $\mathrm{HN}_{3}$ as a

\footnotetext{
* Corresponding author. Tel.: +886-2-2366-8232; fax: + 886-22632-0200.

E-mail address: chenkh@po.iams.sinica.edu.tw (K.-H. Chen).
}

nitrogen source [14]. However, high quality $\mathrm{InN}$ has not been achieved mainly due to the lack of a latticematched substrate and restricted growth conditions owing to low dissociation temperature of InN itself [15]. Normally the growth temperature should be kept relatively low $\left(\sim 500{ }^{\circ} \mathrm{C}\right)$ to prevent the dissociation of InN. However, the limited cracking efficiency of $\mathrm{N}_{2}$ or $\mathrm{NH}_{3}$ at such temperatures results in a relatively low growth rate. In this paper, we report the growth of nanocrystalline $\mathrm{InN}$ on $\mathrm{Si}(111)$ with a growth rate of 6 $\mu \mathrm{m} / \mathrm{h}$ using a double zone MOCVD system.

\section{Experimental}

A schematic diagram of the MOCVD apparatus for the $\mathrm{InN}$ growth is shown in Fig. 1. Trimethylindium [TMIn: $\left(\mathrm{CH}_{3}\right)_{3} \mathrm{In}$ ] kept at $10{ }^{\circ} \mathrm{C}$ and high-purity $\mathrm{NH}_{3}$ were used as the precursors. TMIn vapor was carried by $40-80 \mathrm{sccm}$ high-purity $\mathrm{N}_{2}$ gas and another 200 sccm $\mathrm{N}_{2}$ gas was added down stream to increase the gas flow of the group-III line. The $\mathrm{NH}_{3}$ flow rate was varied from 800 to $1600 \mathrm{sccm}$, which corresponds to a $\mathrm{V} / \mathrm{III}$ ratio of several hundreds. To prevent pre-reaction 


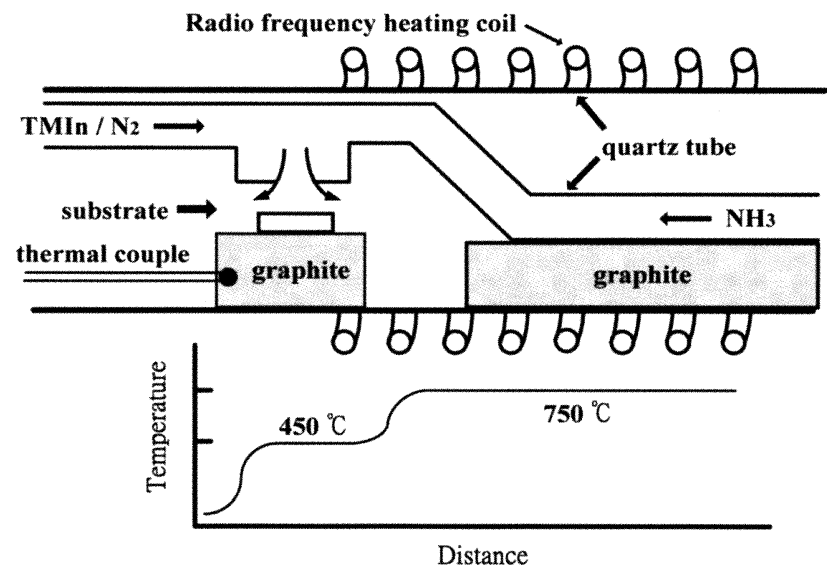

Fig. 1. Configuration and temperature distribution of the double zone MOCVD reactor for InN growth.

between TMIn and $\mathrm{NH}_{3}$, the two gases were fed into the chamber through separate quartz tubes. The tube delivering $\mathrm{NH}_{3}$ passed over a high temperature graphite zone of $600-900{ }^{\circ} \mathrm{C}$ to enhance $\mathrm{NH}_{3}$ cracking. The preheated $\mathrm{NH}_{3}$ gas was mixed with TMIn right above the substrate and injected vertically onto the substrate. Prior to placing the $\mathrm{Si}(111)$ substrates into the reactor, the substrates were first cleaned in an acetone and then methanol ultrasound bath for $3 \mathrm{~min}$ each, followed by subsequent cleaning in $8 \%$ HF solution and deionized water, and finally dried in nitrogen gas. The substrate temperature during growth can be varied from 400 to $600{ }^{\circ} \mathrm{C}$. Typical temperature profile of the chamber was shown in the lower part of Fig. 1. TMIn was introduced to the chamber before $\mathrm{NH}_{3}$ to prevent amorphous $\mathrm{SiN}_{x}$ formation, which was reported to severely degrade the film quality [8]. The films thus deposited were characterized by XRD using a Rigaku D/MAX C diffractometer. The morphology and the thickness, typically 0.2 $-6 \mu \mathrm{m}$, of the films were studied using a Hitachi S800 scanning electron microscope (SEM). The structure and lattice image of the film were studied using a Philips CM200 transmission electron microscope (TEM). Raman spectra were obtained through a Renishaw system 2000 micro-Raman spectrometer with an $\mathrm{Ar}^{+}$laser as the light source.

\section{Results and discussion}

Fig. 2 displays a typical $\theta-2 \theta$ XRD scan showing strong $\operatorname{InN}(0002), \operatorname{InN}(0004)$ and $\mathrm{Si}(111)$ peaks at $31.3^{\circ}, 65.3^{\circ}$ and $28.4^{\circ}$, respectively, indicating that hexagonal $\mathrm{InN}(\mathrm{h}-\mathrm{InN})$ is grown with strong (0001) texture on the $\mathrm{Si}(111)$ substrate. The lattice constant obtained from the XRD data is $5.73 \AA$. Besides the InN(0002) peak, additional small peaks corresponding to InN $(10-11),(10-12),(10-13)$ indicate the polycrystalline nature of the film. Typical SEM images (not

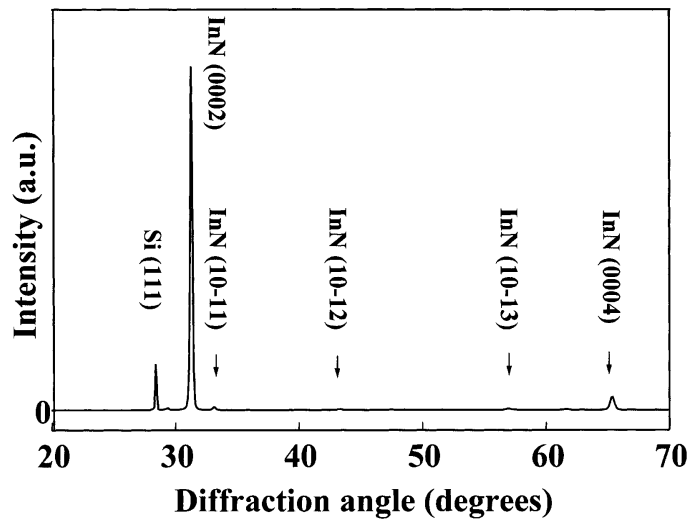

Fig. 2. XRD $\theta-2 \theta$ scan of the $\operatorname{InN} / \mathrm{Si}(111)$ film and its peak assignment.

shown here) of the film indicate columnar structure, which is typical for CVD growth of lattice-mismatched materials. The top view reveals fine grain structures with hexagonal pyramids, which is common for film growth with a lattice mismatch larger than $4 \%$ ( $8 \%$ in our case). The large mismatch in our system even resulted in cracking of the films when the thickness exceeded $1 \mu \mathrm{m}$. Therefore, the thickness of the sample was kept below $0.6 \mu \mathrm{m}$ to avoid cracking of the films.

The Raman spectrum of a typical $\mathrm{InN} / \mathrm{Si}(111)$ film is shown in Fig. 3. The h-InN related peak at $487 \mathrm{~cm}^{-1}\left(\mathrm{E}_{2}\right.$ mode) could be clearly identified. The $\mathrm{A}_{1}(\mathrm{LO})$ modes shifted toward lower wavenumber at $583 \mathrm{~cm}^{-1}$. Both peaks were broadened with respect to those reported in the literature $[16,17]$. This broadening may be attributed to strain and defects in our film.

The temperature dependence of the $\mathrm{InN}$ growth rate is shown in Fig. 4. In Fig. 4a, the growth rate as a function of substrate temperature without $\mathrm{NH}_{3}$ preheating is shown. As expected, the growth rate increases with substrate temperature. However, it starts to decrease when the substrate temperature is above $500{ }^{\circ} \mathrm{C}$, presumably due to the dissociation of InN. A maximum growth

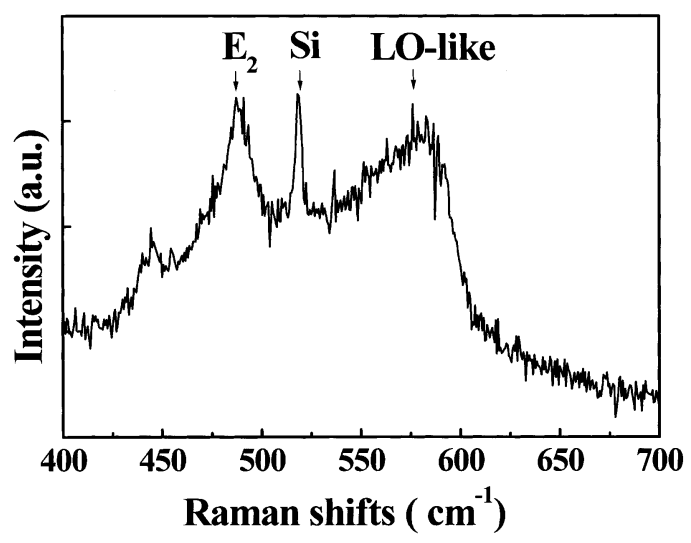

Fig. 3. Raman spectrum of the $\mathrm{InN} / \mathrm{Si}(111)$ film. 
rate of $1.5 \mu \mathrm{m} / \mathrm{h}$ at $500{ }^{\circ} \mathrm{C}$ is obtained, which is relatively high compared to published works [4]. When additional graphite was inserted for preheating $\mathrm{NH}_{3}$ to form the double zone system, a strong temperature dependence of the growth rate was observed. As shown in Fig. $4 \mathrm{~b}$ at a fixed substrate temperature of $500{ }^{\circ} \mathrm{C}$, a maximum growth rate of $6 \mu \mathrm{m} / \mathrm{h}$ is achieved at a $\mathrm{NH}_{3}$ preheating temperature of $750{ }^{\circ} \mathrm{C}$. The high growth rate is attributed to the highly efficient $\mathrm{NH}_{3}$ cracking at elevated preheating temperature. However, too high a temperature would cause heating of the adjacent substrate surface and resulted in the dissociation of the InN. Although the V/III ratio of our growth condition is much lower than those reported in the literature [3,4], no indium droplets were observed on the surface, indicating sufficient supply of active nitrogen due to the efficient $\mathrm{NH}_{3}$ cracking in the double zone system.

To study the detailed structure of the InN film thus grown, HRTEM is applied to investigate the structure and the lattice image. As shown in the cross-sectional image of the film in Fig. 5, nanocrystallites of approximately $10 \mathrm{~nm}$ diameter are observed throughout the film. It should be pointed out that the long wavelength fringes (as circled) in the figure is attributed to the interference of waves from neighboring grains misoriented with a small azimuthal angle to each other. This implies that these nanocrystallites are highly oriented to each other. The TEM diffraction (TED) of the sample is depicted in the inset of the figure, showing a discrete diffraction spot with twofold symmetry, indicating highly oriented crystals despite the polycrystalline nature of the film. The orientation of the crystallites is also reflected in the XRD pattern in Fig. 2, wherein the (0002) peak dominates the entire spectrum. A detailed calculation using the $0.3^{\circ}$ FWHM of the (0002) peak and $0.1^{\circ}$ instrumental resolution, we obtained an average grain size of $30 \mathrm{~nm}$ from the Scherrer equation [18]. This is comparable to the $10-\mathrm{nm}$ grain size measured directly from the TEM image.

After calibrating the camera constant of the TED photograph using a single crystal $\mathrm{Si}$ sample, the d-

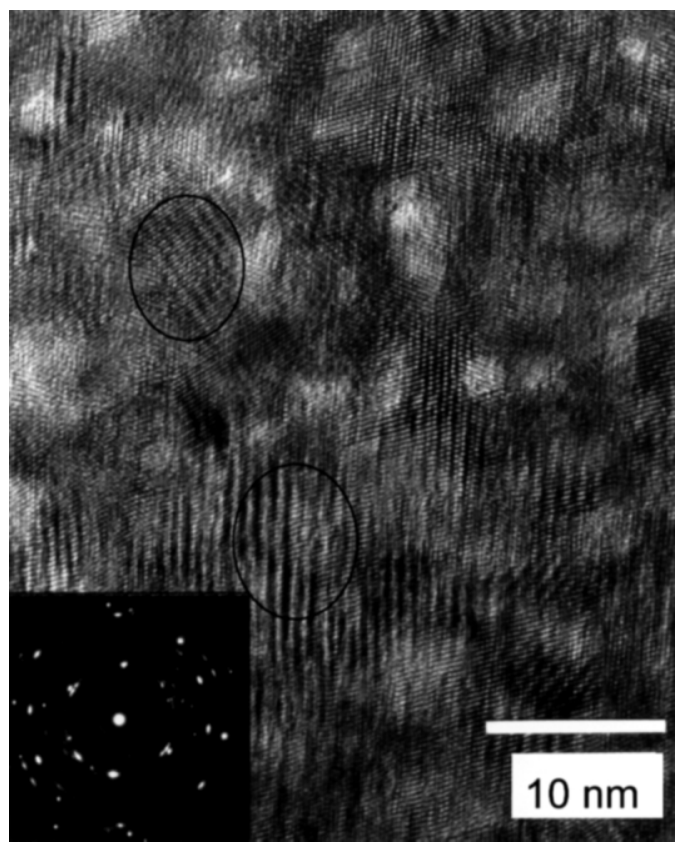

Fig. 5. High resolution cross-sectional TEM image of $\mathrm{InN}$ grown on $\mathrm{Si}(111)$ substrate with the TED at the inset.

spacings of the InN can be obtained from the radius of the spots measured from the center of the diffraction pattern. A computer program was utilized to draw circles (not shown in Fig. 5) from the center of the diffraction pattern to match the diffraction spots and resulted in 14 of them. A comparison of the 14 lattice spacings measured by TED and its corresponding values reported in the literature were listed in Table 1. Small deviation between the lattice spacing values and its corresponding literature values in the table confirms the growth of hexagonal InN films. The lattice constants of $a=3.56$ $\AA$ and $c=5.67 \AA$ were thus determined. To confirm this observation, a direct measurement of the lattice spacing from the lattice image in Fig. 5 yields 3.00, 2.82 and $2.10 \AA$, which agree well with the lattice spacing of $(10-10),(0002)$ and $(10-12)$ planes, respectively.
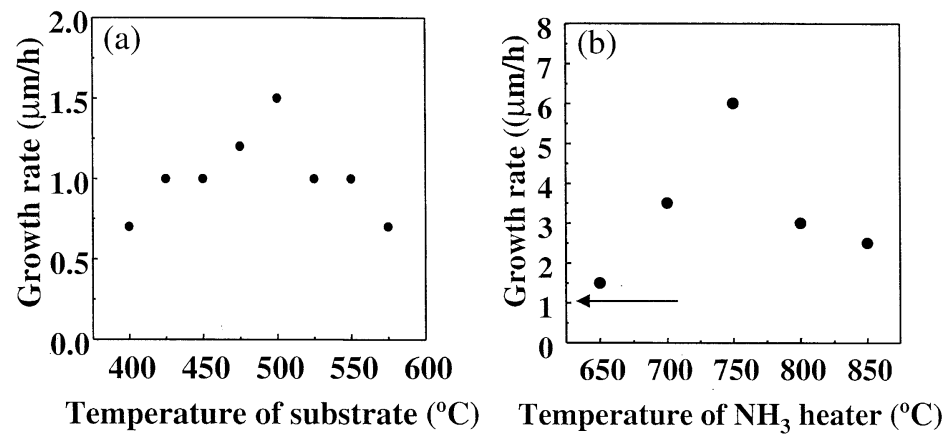

Fig. 4. (a) The growth rate of $\mathrm{InN}$ as a function of substrate temperature without $\mathrm{NH}_{3}$ preheating. (b) The growth rate as a function of preheating graphite temperature at a substrate temperature of $500{ }^{\circ} \mathrm{C}$. The arrow in the figure indicates the reported growth rate in the literature. 
Table 1

Comparison of the lattice spacing measured using TED and the corresponding data $(a=3.5366 \AA, c=5.7009 \AA)$ reported in the literature [21]

\begin{tabular}{lllc}
\hline $\begin{array}{l}\mathrm{D}(\AA) \\
(\mathrm{TED})\end{array}$ & hkl & $\mathrm{D}(\AA)$ & Deviation $(\%)$ \\
\hline 3.04 & 100 & 3.069 & -0.7 \\
2.90 & 002 & 2.850 & 1.8 \\
2.73 & 101 & 2.700 & 1.1 \\
2.13 & 102 & 2.090 & 1.9 \\
1.79 & 110 & 1.770 & 1.1 \\
1.61 & 103 & 1.613 & -0.6 \\
1.53 & 200 & 1.531 & 0.0 \\
1.51 & 112 & 1.504 & 0.7 \\
1.48 & 201 & 1.478 & 0.0 \\
1.40 & 004 & 1.430 & -2.1 \\
1.33 & 202 & 1.352 & -1.5 \\
1.29 & 104 & 1.291 & 0.0 \\
1.21 & 203 & 1.193 & 1.7 \\
\hline
\end{tabular}

However, the nanocrystalline feature of the HRTEM image is unique to such compounds. The nanocrystalline nature of the $\mathrm{InN}$ films thus grown has also been reported in other systems such as nanocrystal $\mathrm{InN}$ inclusion in $\operatorname{In}_{x} \mathrm{Ga}_{1-x} \mathrm{~N}$ growth $[19,20]$. The fact that the nanocrystalline nature of InN may play an important role in the high efficiency emission of the III-nitride system could lead to a similar effect in the red emission of the InN. The 5-10 nm InN quantum dot, in particular, is highly desirable for optoelectronic applications such as high efficiency, low threshold, high thermal stability lasers. More detailed study is underway to verify such possibilities.

\section{Conclusion}

High growth rate deposition of oriented nanocrystalline InN films using the double zone MOCVD method is reported in this paper. By utilizing an $\mathrm{NH}_{3}$ preheating design, nanocrystalline $\mathrm{InN}$ films were deposited on $\mathrm{Si}(111)$ at a growth rate of $6 \mu \mathrm{m} / \mathrm{h}$, which is fourfold higher than the growth rate reported in the literature. Detailed characterization of the films has been performed using SEM, Raman, XRD and HRTEM. The nanocrystalline nature of the films and high growth rate of the process open up potential for high efficiency, low threshold, low cost and environmentally benign optoelectronic materials including high efficiency solar cells.

\section{Acknowledgments}

Financial support for this project from Academia Sinica, Taiwan is gratefully acknowledged. One of the authors (J.H. Hwang) acknowledges the postdoctoral fellowship awarded by the National Science Council, Taiwan.

\section{References}

[1] T.L. Transley, C.P. Foley, J. Appl. Phys. 59 (1986) 3241.

[2] E.N. Matthias, B.M. Allen, IEEE Trans. Electron Devices, ED34 (1987) 257.

[3] A. Wakahara, T. Tsuchiya, A. Yoshida, J. Cryst. Growth 99 (1990) 385.

[4] M. Sato, Jpn. J. Appl. Phys. 36 (1997) 595.

[5] Q. Guo, M. Nishio, H. Ogawa, A. Yoshida, Jpn. J. Appl. Phys. 38 (1999) L490.

[6] A. Yamamoto, Y. Yamauchi, M. Ohkubo, A. Hashimoto, J. Cryst. Growth 174 (1997) 641.

[7] S. Yamaguchi, M. Kariya, S. Nitta, T. Takeuchi, C. Wetzel, H. Amano, I. Akasaki, J. Appl. Phys. 85 (1999) 7682.

[8] Y.C. Pan, W.H. Lee, C.K. Shu, H.C. Lin, C.I. Chiang, H. Chang, S.D. Lin, M.C. Lee, W.K. Chen, J. Appl. Phys. 38 (1999) 645.

[9] A. Yamamoto, M. Tsujino, M. Ohkubo, A. Hashimoto, J. Cryst. Growth 137 (1994) 415.

[10] S.E. Aleksandrov, V.A. Zykov, T.A. Gavrikova, D.M. Krasovitskii, Semiconductors 32 (1998) 412.

[11] T.J. Kistenmacher, S.A. Ecellberger, W.A. Bryden, J. Appl. Phys. 74 (1993) 1684.

[12] C.R. Abernathy, S.J. Pearton, F. Ren, P.W. Wisk, J. Vac. Sci. Technol. B11 (1993) 179.

[13] O. Igaracshi, Jpn. J. Appl. Phys. 31 (1992) 2665.

[14] Y. Bu, L. Ma, M.C. Lin, J. Vac. Sci. Technol. A11 (6) (1993) 2931.

[15] O. Ambacher, M.S. Brandt, R. Dimitrov, T. Metzger, M. Stutzmann, R.A. Fischer, A. Miehr, A. Bergmaier, G. Dollinger, J. Vac. Sci. Technol. B14 (6) (1996) 3532.

[16] M.C. Lee, H.C. Lin, Y.C. Pan, C.K. Shu, J. Ou, W.H. Chen, W.K. Chen, Appl. Phys. Lett. 73 (1998) 2606.

[17] H.J. Kwon, Y.H. Lee, Appl. Phys. Lett. 69 (1996) 937.

[18] B.D. Cullity, Element of X-Ray Diffraction, 2nd ed., Addison Wesley, Reading, MA, 1978, pp. 284-285.

[19] C.C. Liao, S.W. Feng, C.C. Yang, Y.S. Lin, K.J. Ma, C.C Chuo, C.M. Lee, J.I. Chyi, Appl. Phys. Lett. 76 (2000) 318.

[20] H.C. Yang, P.F. Kuo, T.Y. Lin, Y.F. Chen, K.H. Chen, L.C. Chen, J.I. Chyi, Appl. Phys. Lett. 76 (2000) 3712.

[21] W. Paszkowicz, Powder Diffr. 14 (4) (1999) 258. 